\title{
Effect of Cultural Distance on Translation of Culture-Bound Texts
}

\author{
Vahid Rafieyan \\ International College of Liberal Arts, Yamanashi Gakuin University \\ Kofu, Yamanashi, Japan \\ E-mail: rafieyanv@ygu.ac.jp
}

Received: 01-04- 2016

Accepted: 29-04-2016

doi:10.7575/aiac.ijels.v.4n.2p.67

URL: http://dx.doi.org/10.7575/aiac.ijels.v.4n.2p.67

Published: 30-04-2016

\begin{abstract}
Sociolinguistic and sociocultural features of the source language can be ideally transferred to the target language when the translator's cultural background knowledge has a high overlap with the source language culture. This signifies the crucial role of national cultural distance from the source language society in the quality of translation of culture-bound texts. To investigate the actual effect of national cultural distance on the quality of translation of culture-bound texts, the current study was conducted on two groups of participants including 38 German undergraduate students of English translation perceived culturally close to Britons (considered as the target language society) and 32 South Korean undergraduate students of English translation perceived culturally distant from Britons. Data were collected through a culture-bound text consisting of some news excerpts from The British Broadcasting Corporation (BBC) used as the translation quality assessment instrument. The analysis of independent-samples t-test revealed the significant positive effect of national cultural distance on the quality of translation of culture-bound texts. The pedagogical implications of the findings suggested incorporation of cultural features of the source language society into every translation course.
\end{abstract}

Keywords: Culture-Bound Texts, National Cultural Distance, Translation Quality

\section{Introduction}

As there are culture-loaded expressions in every language (Riccardi, 2002), translating from one language into another language involves not only comparing the two languages but also comparing the two cultures (Nord, 2001). Therefore, the cultural values of the source language society and their target language equivalents ought to be considered in the translation process and translators ought to be able to prioritize the social perspectives in their work (Toury, 1995). Translators who come from a country whose cultural features are closer to the cultural features of the source language country are supposed to be more familiar with the cultural features of the source language society as both languages share a lot of cultural features and consequently are supposed to be able to render a more efficient translation than translators who come from countries whose cultural features are distant from the cultural features of the source language country. This clearly signifies the crucial role of national cultural distance in the quality of translation of culture-bound texts.

National cultural distance, which is defined as the degree to which the shared values and norms of a country differ from the shared values and norms of another country, has been presented by Hofstede (2001) in a model which comprises five dimensions of power distance, individualism versus collectivism, masculinity versus femininity, uncertainty avoidance, and Confucian dynamism or short-term versus long-term orientation in life. Power distance is attributed to the degree to which the less powerful members of institutions within a country accept and expect that power is not distributed equally. Individualism, which is opposed to collectivism, is attributed to societies in which ties among people are not strong and people are not integrated into strong and cohesive groups. Masculinity, which is opposed to femininity, is attributed to societies in which social gender roles are obviously distinct and do not overlap, that is, men are tough, assertive, and focused on marital success while women are tender, modest, and focused on the quality of life. Uncertainty avoidance is attributed to the degree to which the members of a society feel threatened by unknown or uncertain conditions and try to stay away from such conditions. Confucian dynamism on short-term orientation pole is attributed to respect for tradition, protecting face, personal steadiness and stability, and reciprocation of favors, gifts, and greetings and on long-term orientation pole is attributed to perseverance, ordering relationships by status, thrift, and having a sense of shame (Rafieyan et al., 2014).

The role of national cultural distance in language learners' language proficiency has been investigated in a number of studies. In one of these studies, Galchenko and Van de Vijver (2007) explored the effect of perceived national cultural distance on the acculturation of a group of exchange students in Russia. Participants of the study comprised two groups of students from a variety of countries on an academic exchange program at various universities in Russia: an Asian group and an African group. A questionnaire assessing exchange students' perceived national cultural distance, acculturation orientations, coping skills, personality, sociocultural outcomes, home domain resources, and psychological outcomes was adopted to gather the data. The results of the study showed that a high perceived national cultural 
distance from the host culture was related to less sociocultural adaptation and more psychological problems. Exchange students from Asian countries reported the highest perceived national cultural distance from Russia, the most stress, the most neuroticism, the least adjustment, and the least active coping strategies while exchange students from African countries demonstrated a lower perceived national cultural distance from Russia, a higher level of extraversion and seeking social support as a coping strategy, and a lower level of neuroticism and stress. Suanet and Van de Vijver (2009) also conducted a study to examine the effect of perceived national cultural distance on the adjustment of a group of exchange students in Russia. The exchange students participating in the study were divided into four groups according to their cultural similarities: an African group, an Asian group, a Latin American group, and a former Soviet Union group. A questionnaire assessing exchange students' perceived national cultural distance, behavioral outcomes, coping skills, psychological outcomes, acculturation orientations, and personality was adopted as the data collection instrument. The results of the study showed that a high perceived national cultural distance was related to more interaction with co-nationals, less interaction with host-nationals, and less psychological adjustment. Exchange students in the Asian group reported the highest perceived national cultural distance from Russia, socialized mostly with conationals, and experienced more stress and homesickness whereas exchange students from former Soviet Union group demonstrated the lowest perceived national cultural distance from Russia, more interaction with host-nationals, and less stress and homesickness. In another study, Rafieyan et al. (2014) examined the significance of national cultural distance between the source language community and the target language community in language learners' level of pragmatic comprehension. A group of German undergraduate learners of English considered culturally close to Britons as the target language society and a group of South Korean undergraduate learners of English considered culturally distant from Britons participated in the study. A multiple choice pragmatic comprehension test was also used as the data collection instrument. The study revealed that language learners with less national cultural distance from the source language society exhibited higher pragmatic comprehension ability than language learners with more national cultural distance from the source language society. Most recently, Rafieyan (2015) investigated the effect of national cultural distance from the target language society as predictor of pragmatic competence on target language writing proficiency. Participants were 30 German undergraduate students perceived as culturally close to Britons as the target language society and 30 South Korean undergraduate students perceived as culturally distant from Britons. To collect data, participants were required to write a letter of application for an English teaching position. The analysis of letters indicated that German students were more proficient in using the appropriate target language pragmatic features in writing than South Korean students.

The studies conducted so far have investigated the effect of national cultural distance on the adjustment of language learners in the new culture as well as language learners' linguistic and pragmatic development. There is, however, a dearth of research on the effect of national cultural distance on the quality of translation of culture-bound texts. Therefore, given the significance of national cultural distance on the familiarity with the cultural features of the source language society on one hand and the significance of familiarity with the cultural features of the source language society on the quality of translation of culture-bound texts on the other hand, the current study seeks to investigate the effect of national cultural distance on the quality of translation of culture-bound texts. In this respect, the research question to be addressed in the current study is:

To what extent does national cultural distance from the source language society affect the quality of translation of culture-bound texts?

Accordingly the null hypothesis is:

National cultural distance from the source language society has no effect on the quality of translation of culture-bound texts.

\section{Methodology}

\subsection{Participants}

Participants in the study consisted of 38 German undergraduate students of English translation and 32 South Korean undergraduate students of English translation at universities in Japan. All participants were at the final year of their studies; thus, they were considered to equally possess a good command of translation ability. Also, they were all selected from among those who demonstrated equal level of English proficiency on a placement test administered prior to the study. The criterion for the selection of German and South Korean participants was the great difference in their national cultural distance from the Great Britain which was determined as the source language country for the current study. According to the survey data collected about the values of 50 countries around the world by Hofstede (2001), Germans were perceived to be culturally very close to Britons and South Koreans were perceived to be culturally very distant from Britons. The national cultural distance between Germany and the Great Britain as well as the national cultural distance between South Korea and the Great Britain, based on the five dimensions of power distance, uncertainty avoidance, individualism/collectivism, masculinity/femininity, and long-term/short-term orientation, is depicted in Table 1. 


\begin{tabular}{lcccccccccc}
\hline Table 1. Index Scores and Ranks for National Cultural Distance \\
\hline Country & Power Distance & \multicolumn{2}{c}{$\begin{array}{c}\text { Uncertainty } \\
\text { Avoidance }\end{array}$} & \multicolumn{2}{c}{$\begin{array}{c}\text { Individualism / } \\
\text { Collectivism }\end{array}$} & \multicolumn{2}{c}{$\begin{array}{c}\text { Masculinity / } \\
\text { Femininity }\end{array}$} & \multicolumn{2}{c}{$\begin{array}{c}\text { Long/Short-Term } \\
\text { Orientation }\end{array}$} \\
\cline { 2 - 12 } & Index & Rank & Index & Rank & Index & Rank & Index & Rank & Index & Rank \\
\hline $\begin{array}{l}\text { Great } \\
\text { Britain }\end{array}$ & 35 & $42-44$ & 35 & $47-48$ & 89 & 3 & 66 & $9-10$ & 25 & $28-29$ \\
\hline Germany & 35 & $42-44$ & 65 & 29 & 67 & 15 & 66 & $9-10$ & 31 & $22-24$ \\
\hline $\begin{array}{l}\text { South } \\
\text { Korea }\end{array}$ & 60 & $27-28$ & 85 & $16-17$ & 18 & 43 & 39 & 41 & 75 & 5 \\
\hline
\end{tabular}

Source: Hofstede (2001, p.500)

\subsection{Instruments}

The instrument used to collect data in the current study consisted of some news excerpts selected from The British Broadcasting Corporation (BBC) which is the public service broadcaster of the United Kingdom. The criterion for selection of news excerpts was the existence of abundant British cultural features. Researcher carefully reviewed current news on the website of BBC and selected news excerpts which contained a large quantity of British cultural features. Moreover, to avoid making the translation task tedious for participants and consequently ensure that participants will focus on rendering a high quality translation of the news excerpts to the best of their knowledge, the length of the selected news was kept within a page limit (275 words).

To measure the validity of the culture-bound text, content-related evidence of validity was used. The researcher wrote out the definition of what he wanted to measure and then gave this definition, along with the culture-bound text and a description of the intended sample, to two professors at a university in Japan who were experts in the field of translation. The professors confirmed that the content and format is consistent with the definition of the variable and the sample of objects to be measured (Fraenkel et al., 2012). To assess the reliability of the culture-bound text, a pilot study was conducted over 28 nonparticipant senior international students of translation at a university in Japan. The reliability coefficient of the culture-bound text assessed through Cronbach's alpha was 0.80 .

\subsection{Procedure}

During the spring semester of the academic year 2016, 70 copies of the culture-bound text which was designed as the data collection instrument for the current study were administered to all 70 students of English translation participating in the study to be translated. Participants were neither informed of the existence of the cultural references of the Great Britain in the culture-bound text nor warned of the significant weight of appropriate transference of these cultural references into the target language according to the sociolinguistic and sociocultural features of the target language in assessing the quality of their translations. Participants were given ample time to render a high quality of translation of culture-bound text to the best of their knowledge and were allowed to use any type of dictionaries they wished to use during the translation test. Following the completion of the translation test, translation slips were collected by the researcher and prepared for the subsequent data analysis.

\subsection{Data Analysis}

To mark the translations, two German and South Korean bilingual professors who were experts in translation rated the quality of translations. The professors marked the translations on a continuum ranging from 0 to 10 , where 0 represented the worst and 10 represented the best quality of translation. Quality of translations was assessed based on House's $(1977,1997)$ functional-pragmatic model which consisted of three steps: (1) the source text was analyzed along the dimensions of Field, Tenor, and Mode. On the basis of findings on the lexical, the syntactic, and the textual level, a text-profile was set up which reflected the individual textual function; (2) the translated text was analyzed along the same dimensions and at the same level of delicacy; (3) the source and translation texts were compared. An assessment of their relative match was established: how the two texts were similar and/or different, given differing linguistic and cultural constraints (Thuy, 2013).

To measure the degree of agreement between the two raters, Cohen's Kappa which is a measure of inter-rater reliability used to measure agreement between two coders (Saldanha \& O'Brien, 2014) was assessed. The analysis of Cohen's Kappa would give a value between -1 and +1 . The interpretation of the values obtained through Cohen's Kappa, according to Landis and Koch (1977), are presented in Table 2. The inter-rater reliability assessed for the translations of culture-bound text was 0.85 which according to the guidelines set by Landis and Koch (1977) indicates an almost perfect agreement between the two raters. For cases which received different ratings, the raters discussed until they reached an agreement. 
Table 2. Interpretation of Cohen's Kappa Values

\begin{tabular}{ll}
\hline Values & Interpretation \\
\hline Smaller than 0.00 & Poor Agreement \\
\hline 0.00 to 0.20 & Slight Agreement \\
\hline 0.21 to 0.40 & Fair Agreement \\
\hline 0.41 to 0.60 & Moderate Agreement \\
\hline 0.61 to 0.80 & Substantial Agreement \\
\hline 0.81 to 1.00 & Almost Perfect Agreement \\
\hline
\end{tabular}

To compare the performance of German and South Korean students of translation on the translation of culture-bound text, an independent-samples t-test, which is used when the mean score on some continuous variable for two different groups of participants is compared (Pallant, 2013), was conducted on the marks assigned to their translations of culturebound text. To provide an indication of the magnitude of the differences between the quality of translations by German students of translation and South Korean students of translation, eta squared which is the most commonly used effect size statistics (Pallant, 2013) was computed. The values obtained from the calculation of eta squared can range from 0.00 to 1.00 and represents the proportion of variance in the dependent variable that is explained by the independent (group) variable (Pallant, 2013). The guidelines for interpreting the values of eta squared, as proposed by Cohen (1988), are presented in Table 3. Finally, the graphical presentation of the performance of German and South Korean students of translation on the translation of culture-bound text was provided. All the analysis was performed using Statistical Package for Social Sciences (SPSS) software, version 22.

Table 3. Interpretation of Eta Squared Values

\begin{tabular}{ll}
\hline Value & Effect Size \\
\hline 0.01 & Small Effect \\
\hline 0.06 & Moderate Effect \\
\hline 0.14 & Large Effect \\
\hline
\end{tabular}

\section{Results}

Table 4 presents the descriptive analysis of the data derived from the translation of culture-bound text. The descriptive analysis of the data presented in the table consists of the number of German and South Korean students of translation participating in the study as well as the overall mean score and standard deviation of marks assigned to the quality of translations of the culture-bound text for each group of participants. The mean scores presented in the table shows the superior performance of German students of translation (mean: 6.26) over South Korean students of translation (mean: 4.53). However, mean score by itself does not show whether the difference in scores is large enough to be considered significant or not. To determine whether the difference between the mean scores obtained by German and South Korean participants is statistically significant or not, the results of the analysis of independent-samples t-test should be considered.

Table 4. Descriptive Analysis of Data

\begin{tabular}{lllcc}
\hline & Groups & $\mathrm{N}$ & Mean & Standard Deviation \\
\hline Performance & Germans & 38 & 6.26 & 1.465 \\
\cline { 2 - 5 } & South Koreans & 32 & 4.53 & 1.741 \\
\hline
\end{tabular}

Table 5 presents the results of the analysis of independent-samples t-test. The first section of the table gives the results of Levene's test for equality of variances. Levene's test for equality of variances tests whether the variance (variation) of scores for the two groups (Germans and South Koreans) is the same or not. The outcome of this test determines which of the t-values that Statistical Package for Social Sciences (SPSS) software provides is the correct one to use. In case the significance value of Levene's test is more than $0.05(\mathrm{p}>0.05)$, the first row of the table, referring to Equal Variances Assumed, must be considered. Nevertheless, in case the significance level of Levene's test is less than or equal to 0.05 ( $\mathrm{p} \leq 0.05$ ), the variances for the two groups (Germans and South Koreans) are considered different and the data violate the assumption of equal variance; subsequently, the second row of the table, referring to Equal Variances Not Assumed, must be considered (Gravetter \& Wallnau, 2013). The Levene's test in the current study indicates F = $1.272, \mathrm{p}=0.263$ which is higher than the cut-off of 0.05 . This implies that the assumption of equal variances has not 
been violated. Thus, the t-value provided in the first row of the table, which refers to Equal Variances Assumed, must be considered.

Table 5. Independent Samples Test

\begin{tabular}{|c|c|c|c|c|c|c|c|c|c|c|}
\hline & & \multicolumn{2}{|c|}{$\begin{array}{c}\text { Levene's Test } \\
\text { for Equality of } \\
\text { Variances }\end{array}$} & \multicolumn{7}{|c|}{ t-test for Equality of Means } \\
\hline & & \multirow[b]{2}{*}{$\mathrm{F}$} & \multirow[b]{2}{*}{ Sig. } & \multirow[b]{2}{*}{$\mathrm{t}$} & \multirow[b]{2}{*}{ df } & \multirow{2}{*}{$\begin{array}{l}\text { Sig. } \\
(2- \\
\text { tailed })\end{array}$} & \multirow[b]{2}{*}{$\begin{array}{c}\text { Mean } \\
\text { Difference }\end{array}$} & \multirow[b]{2}{*}{$\begin{array}{l}\text { Std. Error } \\
\text { Difference }\end{array}$} & \multicolumn{2}{|c|}{$\begin{array}{c}95 \% \\
\text { Confidence } \\
\text { Interval of the } \\
\text { Difference }\end{array}$} \\
\hline & & & & & & & & & Lower & Upper \\
\hline \multirow[t]{2}{*}{ Performance } & $\begin{array}{l}\text { Equal } \\
\text { variances } \\
\text { assumed }\end{array}$ & 1.272 & 0.263 & 4.521 & 68 & 0.000 & 1.732 & 0.383 & 0.968 & 2.496 \\
\hline & $\begin{array}{l}\text { Equal } \\
\text { variances } \\
\text { not } \\
\text { assumed }\end{array}$ & & & 4.454 & 60.851 & 0.000 & 1.732 & 0.389 & 0.954 & 2.509 \\
\hline
\end{tabular}

To find out whether there is a significant difference between the two groups (Germans and South Koreans) or not, the column labeled Sig. (2-tailed) under the section labeled t-test for Equality of Means should be referred to. Since the assumption of equal variances has not been violated, the significance value provided in the first line of the table referred to Equal Variances Assumed should be used. If the significance value is equal to or less than 0.05 ( $\mathrm{p} \leq 0.05)$, there is a significant difference in the mean scores on the dependent variable (translation quality) for each of the two groups. However, if the significance value is above $0.05(\mathrm{p}>0.05)$, there is no significant difference between the two groups (Gravetter \& Wallnau, 2013). The significance value obtained in the current study is 0.000 . As this value is below the required cut-off of 0.05 , there is a statistically significant difference in the mean translation quality for Germans and South Koreans. The mean difference between the two groups is also shown in the table, along with the $95 \%$ confidence interval of the difference showing the lower value and the upper value.

The significance value, however, does not show the size of the difference between the performance of the two groups of participants (Germans and South Koreans). To provide an indication of the magnitude of the difference between the two groups, effect size statistics need to be calculated. There are a number of different effect size statistics, the most commonly used being eta squared (Pallant, 2013). The formula for calculating eta squared, using the information in Table 5, is as follows:

$$
\text { Eta squared }=t^{2} / t^{2}+(N 1+N 2-2)
$$

Replacing with the appropriate values from the table gives:

$$
\text { Eta } \text { squared }=4.521^{2} / 4.521^{2}+(38+32-2)=0.23
$$

The effect size of the difference between the performance of German students of translation and South Korean students of translation on the translation of culture-bound text obtained in the current study is 0.23 which, according to the guidelines proposed by Cohen (1988) presented in Table 3, represents a very large effect size. Expressed as a percentage $(0.23 \times 100=23), 23$ percent of the variance in quality of translations of culture-bound text is explained by national cultural distance from the source language society. The graphical presentation of the performance of German and South Korean students of translation on the translation of culture-bound text is depicted in Figure 1.

\section{Discussion}

The study found that national cultural distance is a strong predictor of translation quality. German undergraduate students of English translation whose culture is considered to be closer to the culture of Britons as the target language society had a better performance on translating culture-bound text than South Korean undergraduate students of English translation whose culture is considered to be distant from the culture of Britons. Therefore, the null hypothesis of the study which states that national cultural distance from the source language society has no effect on the quality of translation of culture-bound texts is rejected.

These findings can be attributed to the level of shared cultural background knowledge between translation students and the source language society. According to Hofstede (2001), German students of translation shared more cultural background knowledge with Britons, who were considered as the source language society for the current study, than South Korean students of translation. This high level of shared cultural knowledge between German students of 
translation and Britons most probably equipped German participants with the necessary tools for cross-cultural translation whereas South Korean students of translation, who did not share much cultural knowledge with Britons, most likely were not equipped with the sociolinguistic and sociocultural knowledge of the source language to enable them successfully transfer the sociolinguistic and sociocultural features of the source language into the target language in accordance with the cultural rules of the target language.

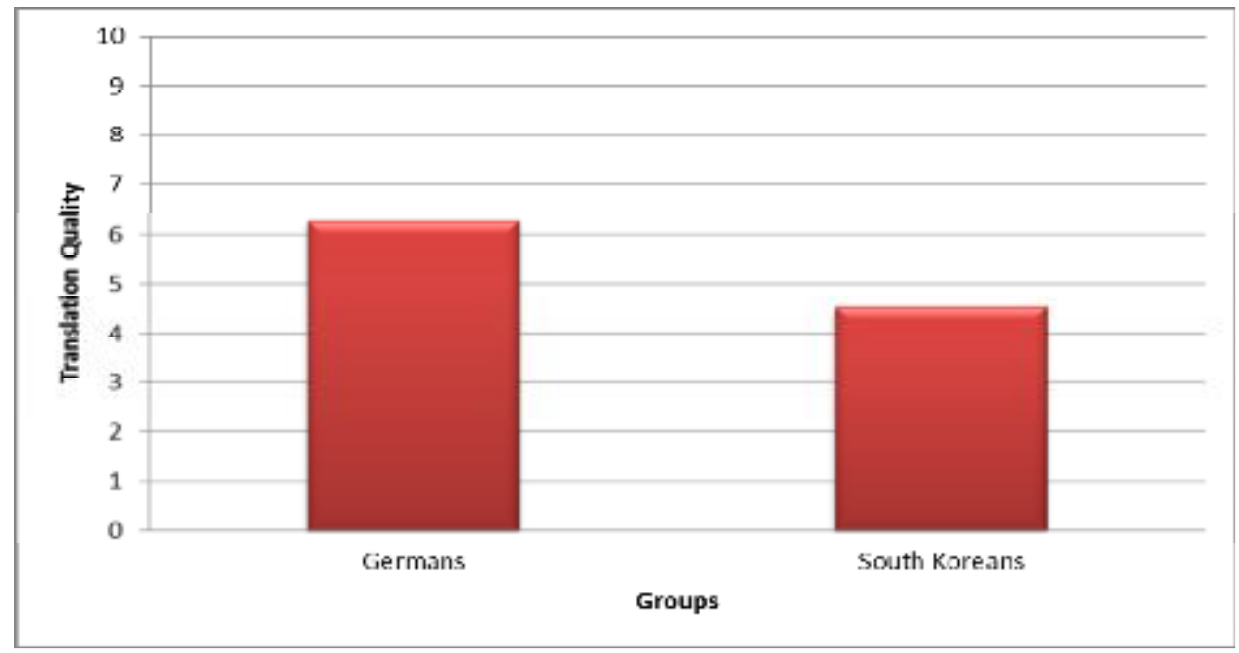

Figure 1. Performance of German and South Korean Students on Translation of Culture-Bound Text

These findings can be also attributed to the fact that German students of translation had more opportunities to be exposed to source language culture and have contact with source language speakers than South Korean students of translation. Germany is geographically close to the Great Britain and Germans have abundant opportunities to visit or to be visited by Britons. This high level of exposure to source language culture and contact with source language speakers most likely provided them with the sociolinguistic and sociocultural knowledge of source language required for a successful cross-cultural translation. However, South Korea is very far from the Great Britain and South Koreans do not have a lot of opportunities to meet Britons frequently. The only way they can be exposed to source language culture is through media and internet which cannot be as effective as direct exposure and contact. Consequently, they do not have the chance to gain sociolinguistic and sociocultural knowledge of the source language and the subsequent cross-cultural translation ability.

The findings obtained in the current study support the findings obtained in the study conducted by Rafieyan et al. (2014) who found that German language learners who were perceived culturally close to Britons comprehended British pragmatic features better than South Korean language learners who were perceived culturally distant from Britons. The findings obtained in the current study are also in line with those obtained in the study conducted by Rafieyan (2015) who discovered that German learners of English were more proficient in using the appropriate pragmatic features in writing according to British sociolinguistic and sociocultural features than South Korean language learners.

\section{Conclusion}

The study revealed the significant positive effect of national cultural distance on the quality of translation of culturebound texts. German students of translation who were perceived culturally close to Britons as the target language society presented translation of culture-bound text at higher standard and more appropriately according to British sociolinguistic and sociocultural knowledge than South Korean students of translation who were perceived culturally distant from Britons. Therefore, considering the significance of possessing cultural background knowledge of the source and target languages in successful transference of culturally bound expressions from the source language into the target language, instructors of translation courses are advised to incorporate cultural features of the source language society into every translation course to train culturally competent translators (Elyildirim, 2008; Rafieyan et al., 2013a; Rafieyan et al., 2013b; Rafieyan, in press a; Rafieyan, in press b; Rafieyan, in press c).

The study was limited in two ways. Firstly, the study was limited to only two groups of Germans and South Koreans and did not include several participant groups of various nationalities with varying national cultural distances from the source language society in the study. Secondly, there was a very small sample of participants for each group of participants in the study. Considering these limitations, the findings of this study cannot be generalized to all translators with various cultural background knowledge and national cultural distances from the source language society. To obtain more comprehensive findings which can be generalized to the translators of all around the world, it is recommended to include a larger number of participants with a variety of cultural background knowledge and national cultural distances from the source language society in future studies. 


\section{Acknowledgements}

The author would like to acknowledge the contribution of Mohamad Rafieyan.

\section{References}

Cohen, J. (1988). Statistical Power Analysis for the Behavioral Sciences. Hillsdale, NJ: Lawrence Erlbaum Associates.

Elyildirim, S. (2008). The Importance of Cultural Knowledge in Translation: A Partial Replication of Olk (2003). Sosyal Bilimler Dergisi, 17, 131-144.

Fraenkel, J. R., Wallen, N. E., \& Hyun, H. H. (2012). How to Design and Evaluate Research in Education (8th ed.). New York: McGraw-Hill.

Galchenko, I., \& Van de Vijver, F. J. R. (2007). The Role of Perceived Cultural Distance in the Acculturation of Exchange Students in Russia. International Journal of Intercultural Relations, 31(2), 181-197. http://dx.doi.org/10.1016/j.ijintrel.2006.03.004

Gravetter, F. J., \& Wallnau, L. B. (2013). Statistics for the Behavioral Sciences (9th ed.). Belmont, C A: Wadsworth Publishing.

Hofstede, G. (2001). Culture's Consequences: Comparing Values, Behaviors, Institutions and Organizations across Nations. Thousand Oaks, CA: Sage Publications.

House, J. (1977). A Model for Translation Quality Assessment. Tubingen: Narr.

House, J. (1997). Translation Quality Assessment: A Model Revisited. Tubingen: Narr.

Landis, J. R., \& Koch, G. G. (1977). The Measurement of Observer Agreement for Categorical Data. Biometrics, 33(1), 159-174. http://dx.doi.org/10.2307/2529310

Nord, C. (2001). Translating as a Purposeful Activity - Functional Approaches Explained. Shanghai: Shanghai Foreign Language Education Press.

Pallant, J. (2013). SPSS Survival Manual: A Step by Step Guide to Data Analysis Using SPSS Program (5th ed.). Australia: Allen \& Unwin.

Rafieyan, V., Norazman, A. M., \& Lin, S. E. (2013a). Relationship between Attitude toward Target Language Culture Instruction and Pragmatic Comprehension Development. English Language Teaching, 6(8), 125-132. http://dx.doi.org/10.5539/elt.v6n8p125

Rafieyan, V., Lin, S. E., \& Abdul-Rashid, M. (2013b). Language Learners' Attitudes towards the Incorporation of Target Language Culture into Foreign Language Instructions. International Journal of Linguistics, 5(4), 169-177. http://dx.doi.org/10.5296/ijl.v5i4.4193

Rafieyan, V., Sharafi-Nejad, M., Khavari, Z., Damavand, A., \& Lin, S. E. (2014). Relationship between Cultural Distance and Pragmatic Comprehension. English Language Teaching, 7(2), 103-109. http://dx.doi.org/10.5539/elt.v7n2p103

Rafieyan, V. (2015). Effect of National Cultural Distance as Predictor of Pragmatic Competence on Writing Proficiency. Research on Humanities and Social Sciences, 5(18), 122-129.

Rafieyan, V. (in press a). Effect of 'Focus on Form' versus 'Focus on Forms' Cultural Instruction on Translation of Culture-Bound Texts.

Rafieyan, V. (in press b). Effect of Telecollaboration on Translation of Culture-Bound Texts. International Journal of Applied Linguistics \& English Literature, 5(4), 127-134.

Rafieyan, V. (in press c). Relationship between Cultural Intelligence and Translation of Culture-Bound Texts. Journal of Applied Linguistics and Language Research, 3(3).

Riccardi, A. (2002). Translation and Interpretation. In A. Riccardi (Eds.), Translation Studies: Perspectives on an Emerging Discipline (pp. 75-91). Cambridge: Cambridge University Press.

Saldanha, G., \& O’Brien, S. (2014). Research Methodologies in Translation Studies. New Tork, NY: Routledge.

Suanet, I., \& Van de Vijver, F. J. R. (2009). Perceived Cultural Distance and Acculturation among Exchange Students in Russia. Journal of Community and Applied Social Psychology, 19(3), 182-197. http://dx.doi.org/10.1002/casp.989

Toury, G. (1995). Descriptive Translation Studies and Beyond. Amsterdam: John Benjamins. http://dx.doi.org/10.1075/btl.4

Thuy, P. T. (2013). House's Functional-Pragmatic Model of Translation Assessment and Implications for Evaluating English-Vietnamese Translation Quality. VNU Journal of Foreign Studies, 29(1), 56-64. 